\title{
The Role of the Hydrolysis and Zirconium Concentration on the Structure and Anticorrosion Performances of a Hybrid Silicate Sol-Gel Coating
}

\author{
Maikki Cullen \\ Technological University Dublin, School of Chemical and Pharmaceutical Sciences, Dublin, Ireland \\ Mary O’Sullivan \\ Technological University Dublin, Centre for Research in Engineering Surface Technology (CREST), Dublin, \\ Ireland \\ Aditya Madhan Kumar \\ Indian Institute of Technology (Indian School of Mines), Dhanbad, Department of Chemical Engineering, \\ Dhanbad, India
}

See next page for additional authors

Follow this and additional works at: https://arrow.tudublin.ie/cenresart

Part of the Chemistry Commons

\section{Recommended Citation}

Cullen, M., O'Sullivan, M. \& Kumar, A.M. (2018). The role of the hydrolysis and zirconium concentration on the structure and anticorrosion performances of a hybrid silicate sol-gel coating. Journal of Sol-Gel Science and Technology, vol. 86, no. 3, pg. 553-567 doi:10.1007/s10971-018-4657-3

This Article is brought to you for free and open access by the Crest: Centre for Research in Engineering Surface Technology at ARROW@TU Dublin. It has been accepted for inclusion in Articles by an authorized administrator of ARROW@TU Dublin. For more information, please contact arrow.admin@tudublin.ie, aisling.coyne@tudublin.ie,gerard.connolly@tudublin.ie.

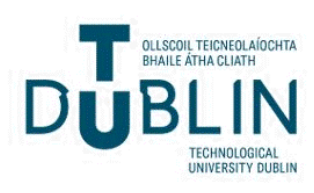




\section{Authors}

Maikki Cullen, Mary O'Sullivan, Aditya Madhan Kumar, Ahmad A. Sorour, Brendan Duffy, and Mohamed Oubaha 


\title{
The role of the hydrolysis and zirconium concentration on the structure and anticorrosion performances of a hybrid silicate sol-gel coating
}

\author{
M. Cullen ${ }^{1,2} \cdot$ M. O'Sullivan ${ }^{2} \cdot$ A. Madhan $\mathrm{Kumar}^{3} \cdot$ A. A. Sorour ${ }^{3} \cdot$ B. Duffy ${ }^{1,2} \cdot$ M. Oubaha $\mathbb{D}^{2}$
}

Received: 9 January 2018 / Accepted: 6 April 2018

(c) Springer Science+Business Media, LLC, part of Springer Nature 2018

\begin{abstract}
In sol-gel chemistry, hydrolysis is the key step in the formation of the reactive hydroxide groups that are responsible for the formation of inorganic networks via the occurrence of condensation reactions. Though previous studies have investigated the effect of the hydrolysis conditions on the structure of organically modified silicates (ormosils), no study, to our knowledge, has investigated this variable on the structure of hybrid materials prepared by combinations of an ormosil and a transition metal (TM). Here, we propose to investigate this effect in a hybrid material composed of 3-trimethoxysilylpropylmethacrylate and a zirconium complex. To also highlight the effects of the precursor's concentrations on the hydrolysis and condensation reactions of the hybrid materials, their relative content was altered along with the hydrolysis degree. The anticorrosion barrier properties were identified by characterisation of coatings deposited on AA2024-T3 substrates and correlation between the structure and the anticorrosion properties of the coatings were performed based on results obtained from structural characterisations (DLS, FTIR, ${ }^{29} \mathrm{Si}$-NMR, DSC, AFM and SEM) and corrosion testing (EIS and NSS). It is demonstrated that competition in the formation of siloxane and Si-O-Zr bonds takes place and can be controlled by the degree of hydrolysis and the concentration of the zirconium complex. This effect was found to dramatically alter the morphology of the coatings and their subsequent anticorrosion performances. At shortterm exposure times, it is found that the most condensed materials exhibited a higher corrosion resistance while over longer periods the performances were found to level. This article highlighted the critical impact of the hydrolysis degree and zirconium concentration on the connectivity of hybrid sol-gel coatings and the impact this has on corrosion performances.
\end{abstract}

M. Oubaha

mohamed.oubaha@dit.ie

1 School of Chemical and Pharmaceutical Sciences, Dublin Institute of Technology, Kevin Street, Dublin 8, Ireland
2 Centre for Research in Engineering Surface Technology, FOCAS Institute, Dublin Institute of Technology, 13 Camden Row, Dublin 8, Ireland

3 Centre of Research Excellence in Corrosion, King Fahd University of Petroleum and Minerals, Dhahran 31261, Saudi Arabia 


\section{Graphical Abstract}

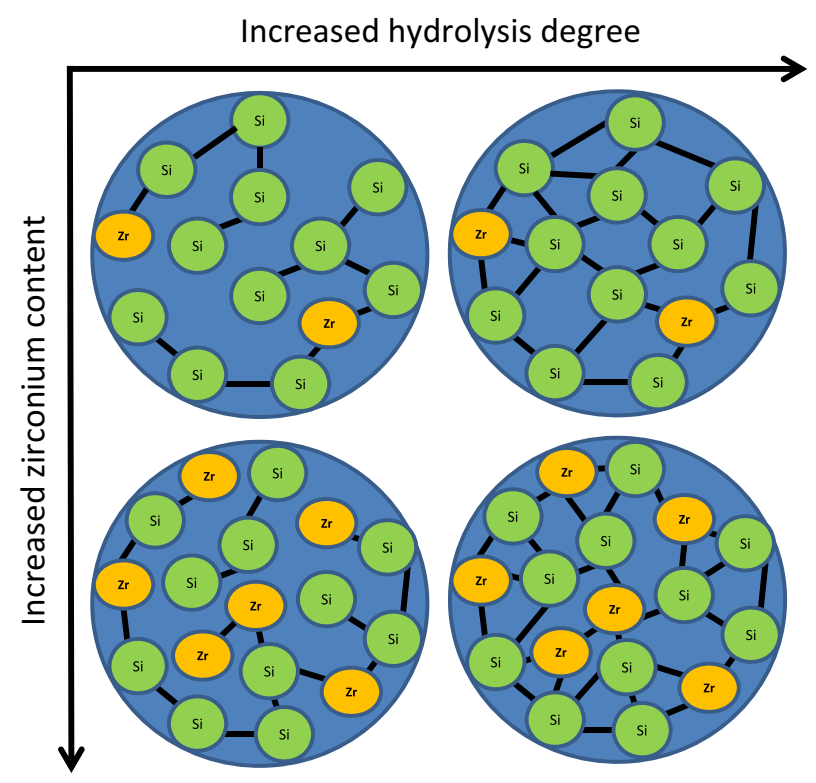

Keywords: $\quad$ Sol-Gel $\cdot$ Hybrids $\cdot$ Silica/Zirconia $\cdot$ Coatings $\cdot$ Hydrolysis $\cdot$ Condensation $\cdot$ Anticorrosion $\cdot$ Structure

\section{Highlights}

- Conjugated effects of the hydrolysis degree and transition metal concentration on the structure and anticorrosion properties of hybrid sol-gel coatings are investigated.

- Correlation between the structure and anticorrosion performances of hybrid sol-gel coatings is proposed. The structure of the materials is characterised by 29Si-NMR, FTIR, DLS, DSC, AFM and SEM, while the anticorrosion performances are identified by EIS and NSS.

- The condensation of the coatings is found to be strongly relying on the hydrolysis degree and transition metal concentration.

- The short term anticorrosion performances are optimum for highly condensed coatings, while long term resistances are similar regardless of the condensation of the coatings.

- The nature of the coating/metal interface is dependent on the condensation of the materials.

\section{Introduction}

The development of eco-friendly coatings for the protection of metallic surfaces against environmental corrosion has been extensively investigated in the past decade in order to comply with environmental and health regulations, which limits the use of some heavy metals, such as hexavalent chromium [1, 2]. Recent reviews have comprehensively listed different process alternatives developed for the replacement of chromate (VI)-based coatings [3, 4]. These processes include passivation, anodisation, chemical conversion, ion implantation, cathodic electrodeposition and sol-gel coatings. These processes are based on the use of individual chemistries such as trivalent chromium, phosphate, zinc phosphate, permanganate, rare earth metals, vanadium or combinations of these different compounds. Of these technologies, conversion coatings remain the cheapest and the easiest to process, while providing the mechanical and anticorrosion properties required for commercial applications [5]. However, hybrid sol-gel materials have probably been the family of materials that have attracted the strongest interest from those listed above $[6,7]$ as a viable alternative, with organically modified silicate-based coatings being by far the most popular. The higher focus on these hybrid materials rather than the other listed alternatives is due to several factors. First, a wide range of solgel reactive functionalised alkoxide silane precursors are commercially available, such as the acryloxysilanes, aminosilanes, epoxysilanes, cyanatosilanes, mercaptosilanes, vinylsilanes and alkylsilanes. In addition to their capability to form three-dimensional inorganic networks, these precursors can provide functional groups at the surface of the coatings. For example, mercaptosilanes have been used to functionalise glass surfaces for the immobilisation of 
biological species [8], epoxysilanes have been employed to improve the adhesion properties of organic coatings [9] and acryloxysilanes have been used to provide photoreactivity for the fabrication of miniature devices [10] and microstructuring of optical devices [11]. Second, these organosilane sol-gel matrices are capable of hosting organic and inorganic doping elements to further provide desirable characteristics for specific applications. For example, inorganic inhibitors such as vanadates, molybdates, permanganates and cerium salts $[12,13]$, as well as organic inhibitors such as quinaldic acid, betaine, dopamine hydrochloride, diazolidinyl urea and tetrazines $[14,15]$ have been incorporated within silicate-based sol-gel matrices to improve their anticorrosion properties. Network modifiers such as transition metal (TM) alkoxides or ionic liquids have been incorporated within silicate-based materials to adjust the optical [16, 17], electrical [18] or surface morphology of inorganic surfaces [19].

Sol-gel coatings prepared from combinations of TMs and organosilane alkoxides exhibit physicochemical properties, including morphology, mechanical and surface features, which rely on the interactions between the TM and the silicate precursor. In addition, the preparation conditions that include the nature and functionality of the precursors, $\mathrm{pH}$ and rate of hydrolysis, as well as stabilisation temperature will play an essential role in the condensation process of the precursors, which will determine the final physicochemical properties of the coatings. Therefore, determining the impact of these variables on the structure of the coatings is vital to optimise the coatings formulation that would approach or exceed the properties of hexavalent chromium, performed best as anticorrosion systems.

Recently, the authors have investigated the effect of the content of a zirconium complex within an organosilane matrix composed of 3-trimethoxysilylpropylmethacrylate on the physicochemical properties and corrosion resistance of coatings exposed to a corrosive environment [20]. It was demonstrated that for a fixed hydrolysis degree, the concentration of zirconium complex plays a critical role, with respect to the condensation process of the organosilane matrix, and that the mostly condensed material was prepared using a $20-30 \%$ molar concentration of the zirconium complex, which also exhibited the best anticorrosion performance. The hydrolysis degree being defined by the ratio of water to the reactive alkoxide groups $\left(\mathrm{H}_{2} \mathrm{O} / \mathrm{M}-\mathrm{OR}\right)$. This study suggested that further improvement on the condensation of the coatings could be performed by optimising the degree of hydrolysis. Babonneau et al. investigated the effect of hydrolysis degrees on both single and dual ormosil systems and pioneered the characterisations of hybrid materials using both ${ }^{29} \mathrm{Si}$ and ${ }^{17} \mathrm{O}$ NMR [20-22]. However, to our knowledge, no study reported the effect of the hydrolysis degree on the structure and corrosion properties of hybrid systems composed of both ormosils and TMs.

Therefore, the aim of this article is to identify the impact of the degree of hydrolysis on the physicochemical properties of a typical hybrid material composed of an organosilane and a TM alkoxide, including its structure, morphology, thermal and corrosion resistance. The materials were analysed by dynamic light scattering (DLS), Fourier transform infrared spectroscopy (FTIR), silicon nuclear magnetic resonance $\left({ }^{29} \mathrm{Si}-\mathrm{NMR}\right)$, differential scanning calorimetry (DSC) and scanning electron microscopy (SEM). The anticorrosion performances were evaluated by neutral salt spray (NSS) and electrochemical impedance spectroscopy (EIS). Hypotheses on how these variables affect the structure, morphology and anticorrosion barrier properties of the coatings are proposed.

\section{Materials and methods}

\subsection{Materials}

The sol-gel synthesis was performed in a three-step process employing MAPTMS (3-methacryloxypropyltrimethoxysilane, Assay 99\% in methanol, Aldrich) and ZPO (zirconium (IV) n-propoxide, Assay 70\% in propanol, Aldrich) as alkoxide precursors and MAAH (methacrylic acid, $\mathrm{C}_{4} \mathrm{H}_{6} \mathrm{O}_{4}$, Assay $>98 \%$, Aldrich) as a complexing agent to the ZPO, as described recently [23]. Here, the content of the ZPO complex has been varied along with the hydrolysis degree $\left(\mathrm{HD}=\mathrm{H}_{2} \mathrm{O} / \mathrm{M}-\mathrm{OR}\right.$, where $\mathrm{M}=\mathrm{Si}$ or $\mathrm{Zr}$ ) to evaluate their impacts on the physicochemical properties of the materials, as summarised in Table 1. The materials prepared with a $50 \%$ hydrolysis degree (B, E, H and $\mathrm{K}$ ) have been reported in reference Cullen et al. [23] but are presented

Table 1 Material formulations

\begin{tabular}{llll}
\hline $\begin{array}{l}\text { Sample } \\
\text { name }\end{array}$ & $\begin{array}{l}\text { Sample } \\
\text { series }\end{array}$ & $\begin{array}{l}\text { Hydrolysis degree } \\
(\%)\end{array}$ & $\begin{array}{l}\text { MAPTMS/ZPO/ } \\
\text { MAAH }\end{array}$ \\
\hline A & Series 1 & 75 & $95 / 5 / 5$ \\
B & Series 1 & 50 & $95 / 5 / 5$ \\
C & Series 1 & 25 & $95 / 5 / 5$ \\
D & Series 2 & 75 & $90 / 10 / 10$ \\
E & Series 2 & 50 & $90 / 10 / 10$ \\
F & Series 2 & 25 & $90 / 10 / 10$ \\
G & Series 3 & 75 & $80 / 20 / 20$ \\
H & Series 3 & 50 & $80 / 20 / 20$ \\
I & Series 3 & 25 & $80 / 20 / 20$ \\
J & Series 4 & 75 & $70 / 30 / 30$ \\
K & Series 4 & 50 & $70 / 30 / 30$ \\
L & Series 4 & 25 & $70 / 30 / 30$ \\
\hline
\end{tabular}


here as comparison with the other materials prepared with other hydrolysis degrees.

\subsection{Methods}

The coatings have been prepared by spin coating the sols at $1000 \mathrm{rpm}$ under a $95 \%$ isopropanol-saturated environment on AA2024-T3 aluminium panels. Prior to coating, the panels were degreased, deoxidised and hydroxylised with isopropanol, an aqueous hydrofluoric acid solution and an aqueous sulphuric acid solution, respectively. With these deposition conditions, the evaporation of the solvents is dramatically slowed-down resulting in the fabrication of highly homogenous and residue-free coatings. The final stabilisation of the coatings consisted of curing at $120^{\circ} \mathrm{C}$ for $1 \mathrm{~h}$ in order to achieve touch-dry coatings while minimising the effect of the thermal condensation.

All characterisation techniques employed here namely DLS, FTIR, ${ }^{29}$ Si-NMR, DSC, SEM and EIS have been recently described in detail by us [23].
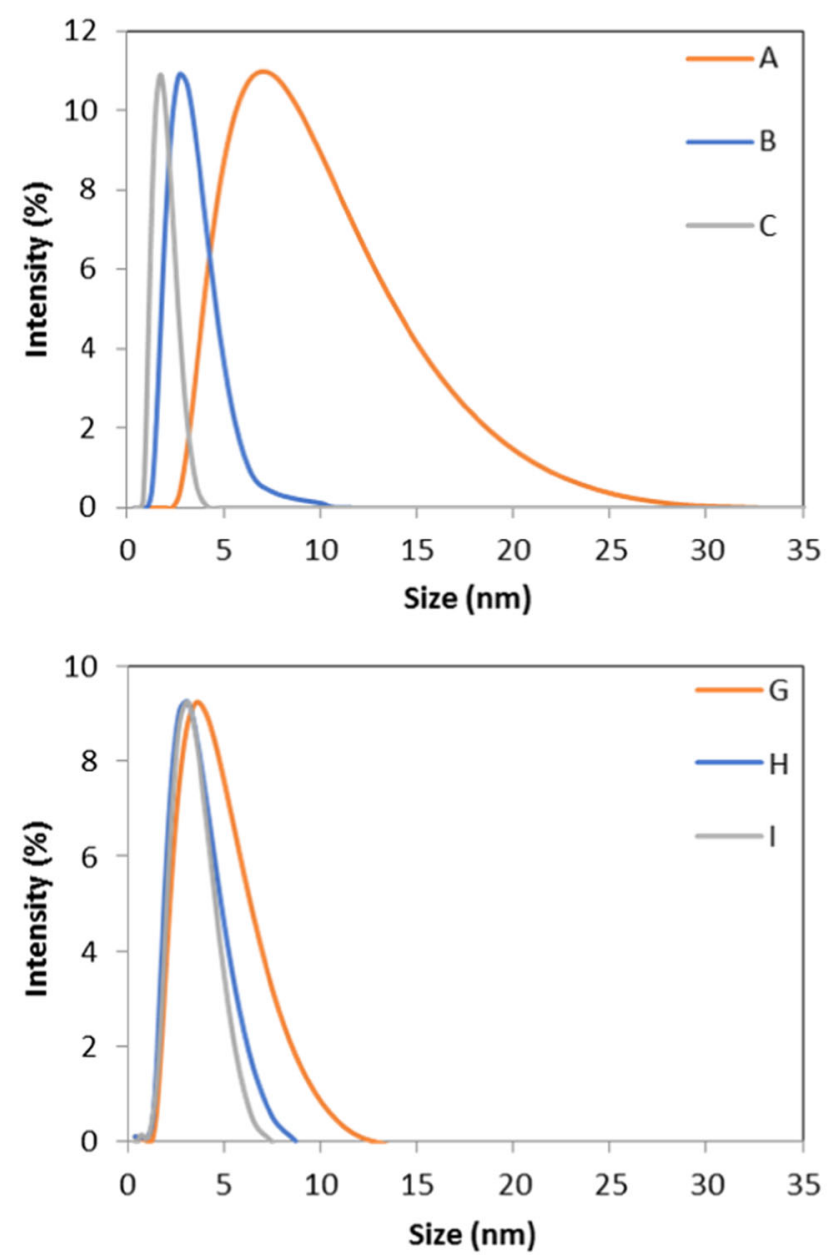

Fig. 1 Size distribution of 24-h aged sols A-L by DLS analysis

\section{Results and discussion}

\subsection{Particle size analysis}

Figure 1 shows particle sizes for 24-h aged sols, there is a monomodal size distribution observed, ranging from 1.5 to $30 \mathrm{~nm}$, with differences observed in the particles sizes and widths of the distribution bands. To determine the dispersion of the nanoparticle populations, the full width at half maximum (FWHM) were measured and presented in Fig. 2. DLS results provide information on the size and homogeneity of the sols and can give early indications of the likely condensation capacity of the materials in the liquid phase during the first 24-h ageing and just prior to coating fabrication [24].

Except for series 4, the particle size increases with an increase in the hydrolysis degree. This indicates that the particles growth relies on the hydrolysis degree and can be explained by the increase of the formation of higher content of reactive silanol and zirconium hydroxide groups. Such
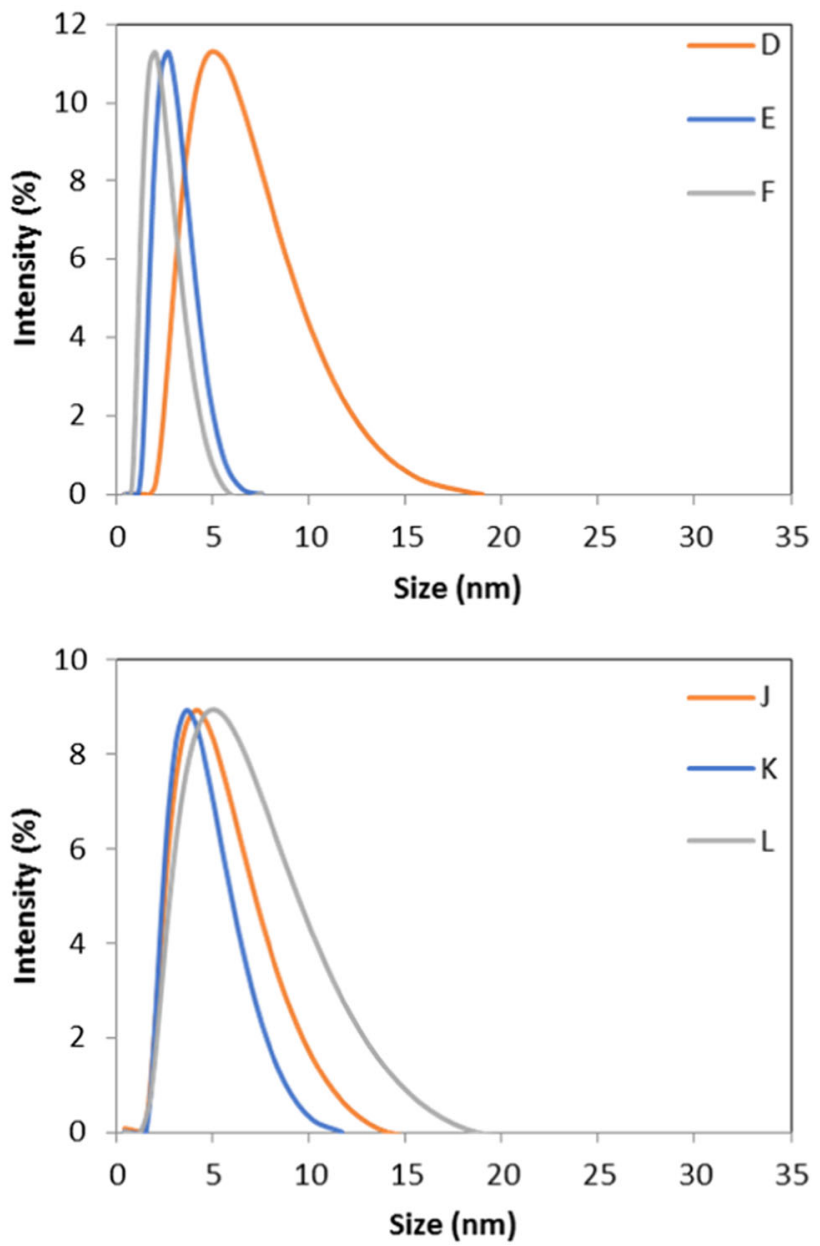


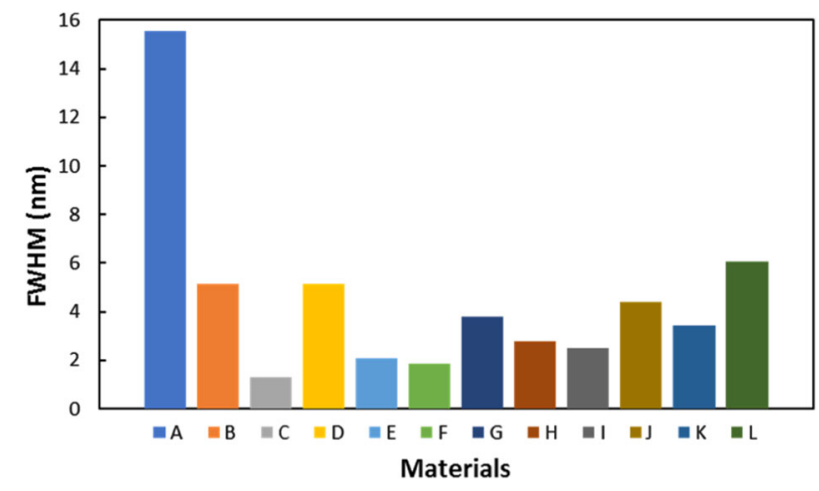

Fig. 2 Full width at half maximum (FWHM) of size distribution of 24$\mathrm{h}$ aged sols A-L by DLS analysis

groups can lead to the formation of condensed siloxane, zirconium oxide and possibly silicon/zirconium oxide groups. However, the fact that this effect is not observed for series 4 , and the impact of the particle size increase is decreasing from series 1 to series 3 , would suggest that the inclusion of the TM within the organosilane network [20] limits the further growth of the nanoparticles. Importantly, this demonstrates that the organosilane is the main system responsible for the growth of the nanoparticles. Owing to this, the observed phenomenon can be ascribed to the effect of the zirconium complex on the reactivity of the organosilane matrix. A possible explanation for this is that the zirconium complex reduces the content of reactive silanol groups into chemical species that are unable to further agglomerate. The most plausible chemical species that can be formed to validate this hypothesis are the $\mathrm{Si}-\mathrm{O}-\mathrm{Zr}$ groups caused by the inorganic condensation of silanol groups with zirconium propoxide or zirconium hydroxide groups. In addition to minimising the condensation ability of the silane network, the anchorage of a zirconium atom at the surface of the silicate network can provoke a steric hindrance that will further limit the condensation of the residual silanol groups situated at the nanoparticle surface to form bigger particles.

In parallel, the positions and widths of the bands related to the materials prepared with 50 and $75 \%$ hydrolysis degrees are found to be similar for series 3 and 4, thus highlighting the stability of materials containing between 20 and $30 \%$ of TM in these hydrolysis conditions. It is also notable that series 3 shows a more homogenous particle size distribution, with the lowest observed FWHMs for each material. Therefore, the concentrations of TM and hydrolysis degree can control the homogeneity of the nanoparticle populations. Based on these results, one can anticipate that the concentration of the TM and the degree of hydrolysis play a critical role in the morphology of the nanomaterials, with one hypothesis proposing the structuration of the organosilane around the TM. This would support the formation of greater silicon-TM oxide bonds. However, the DLS results do not provide information on molecular interactions between the organosilane and the TM and hence the following sections will discuss structural characterisations such as FTIR and ${ }^{29} \mathrm{Si}-\mathrm{NMR}$.

\subsection{FTIR analysis}

The FTIR spectra of each material were recorded on the coatings. Although all materials were prepared employing the same precursors in different concentrations and hydrolysis degrees, the recorded FTIR spectra were found to be similar, exhibiting the same chemical vibrations, as previously shown [20]. However, if the same chemical vibrations were observed, their relative contributions and distributions may be relying on the formulations. To better appreciate the impact of the formulations on the condensation of the materials, a greater focus on the characteristic groups of the inorganic network is required, namely the siloxane ( $\mathrm{Si}-\mathrm{O}-\mathrm{Si}$ ) and silicon-zirconium oxide (Si-O-Zr) related moieties. For this reason, spectra ranging from 800 to $1200 \mathrm{~cm}^{-1}$ are shown in Fig. 3. The FTIR spectrum for material A is not represented in Fig. 3 as dewetting was observed after deposition on the aluminium substrate. All absorption bands have been attributed based on previous references [25-30]. The broad band located in the range $800-1100 \mathrm{~cm}^{-1}$ results from the superimposition of the Si-O-Si $\left(\nu_{\mathrm{s}}\right.$ and $\nu_{\mathrm{as}}$ at $840 \mathrm{~cm}^{-1}$ and $1000-1100 \mathrm{~cm}^{-1}$, respectively), Si-O-Zr $\left(\nu_{\mathrm{s}} 940-950 \mathrm{~cm}^{-1}\right)$ and $\mathrm{Si}-\mathrm{OH}\left(\nu_{\mathrm{s}}\right.$ $890 \mathrm{~cm}^{-1}$ ) stretching vibrations. The methoxysilane symmetric vibrations contained in the MAPTMS are located at $1170 \mathrm{~cm}^{-1}$. Although the large band located in the $1000-1100 \mathrm{~cm}^{-1}$ spectral range represents the asymmetric siloxanes vibrations, in this region four superimposed bands can be distinguished at 1010, 1030, 1055 and $1080 \mathrm{~cm}^{-1}$. Lerot and Low were the first to identify these four bands in purely inorganic silicate materials [31]. In this reference, the band located at $1080 \mathrm{~cm}^{-1}$ was attributed to the stretching vibration of Si-O-Si groups located at the interface between tetrahedral and octahedral units (called silicon apical oxide units), whereas the three other bands (1010, 1030 and $1055 \mathrm{~cm}^{-1}$ ) were assigned to stretching vibrations of siloxane bonds within symmetrical tetrahedral units, requiring less vibration energy than those located at $1080 \mathrm{~cm}^{-1}$. Based on this reference study, in our work, the band located at $1080 \mathrm{~cm}^{-1}$ represents the formation of highenergy siloxane bonds originating from the aggregation of nanostructures of different sizes and possibly different densities. The bands located at 1010, 1030 and $1055 \mathrm{~cm}^{-1}$ represent siloxane bonds within networks of lower connectivity, probably in more porous nanoparticle systems.

The siloxane vibrations located in the range $1010-1200 \mathrm{~cm}^{-1}$ and at $840 \mathrm{~cm}^{-1}$ are observed in all 

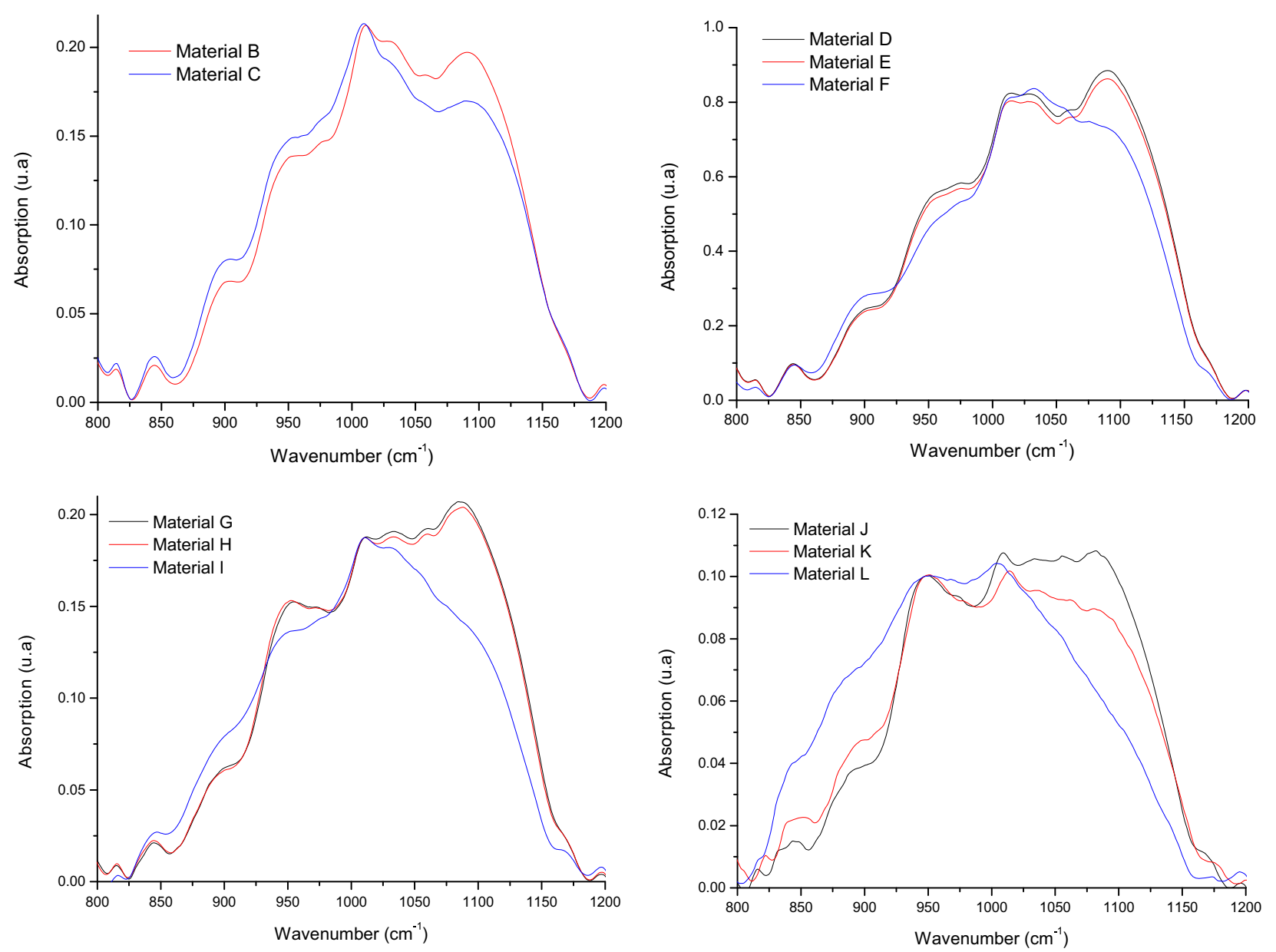

Fig. 3 FTIR spectra of all coatings, ranging from 800 to $1200 \mathrm{~cm}^{-1}$

samples demonstrating the effective sol-gel condensation process of the organosilane. When comparing each series of materials only by varying hydrolysis degrees a similar trend is observed for series $1-3$ in the range $1000-1200 \mathrm{~cm}^{-1}$. As the hydrolysis degree increases, the intensity of the band situated at $1010 \mathrm{~cm}^{-1}$ decreases for the benefit of the three other bands, with the band located at $1080 \mathrm{~cm}^{-1}$ showing the highest intensity for series 3 . Therefore, it is suggested that series 3 would exhibit the highest concentration of high-energy siloxane bonds, thus the siloxane network being in its maximum connectivity. By corroborating the FTIR and DLS results, it can be noted that the increase of the high-energy siloxane bonds is not reflected in any particle growth, with series 3 being the smallest and more homogeneous materials, further confirming that the condensation of the siloxane groups occurs within individual particles even in the liquid phase. Although series 4 also shows an increase of the three highest energy siloxane bonds as the hydrolysis degree increases, the intensity of the band located at $1010 \mathrm{~cm}^{-1}$ appears to be similar to those positioned at higher energy. This similarity suggests that the highest TM concentrations would tend to form equally low- and high-energy siloxane bonds. Also, when analysing the vibration bands related to the silicon-zirconium oxide groups located at $940-950 \mathrm{~cm}^{-1}$, it can be seen that this band decreases for series 1 , suggesting that the increased hydrolysis degree favours the formation of siloxane bonds. However, the $\mathrm{Si}-\mathrm{O}-\mathrm{Zr}$ band is seen to increase for series 2 with the increase of hydrolysis degree at the expense of the silanol and alkoxysilane bands and parallel increase of the siloxane bonds. In series 3, this band is also seen to increase from 25 to $50 \%$ hydrolysis degrees but remain unchanged from 50 to $75 \%$ hydrolysis degrees, with a decrease of the silanol bands taking place similarly. On the contrary, the Si$\mathrm{O}-\mathrm{Zr}$ band does not change in series 4 regardless of the hydrolysis degree. These phenomena can be explained primarily by the formation of different materials morphologies, the first property of which being the density of the formed materials. It is proposed that at low ZPO concentrations, the formation of materials with lower densities takes place, thus explaining the minimum formation of $\mathrm{Si}$ $\mathrm{O}-\mathrm{Zr}$ bonds, whereas at high $\mathrm{ZPO}$ concentrations the formation $\mathrm{Si}-\mathrm{O}-\mathrm{Zr}$ is favoured regardless of the hydrolysis degree. This would mean that the formation of $\mathrm{Si}-\mathrm{O}-\mathrm{Zr}$ 
bonds is mainly due to the ZPO concentration and that the hydrolysis is preferentially performed on the TM, which subsequently condenses with neighbouring silicon species (silanol or methoxysilane groups), the results of which being the formation of high-energy siloxane bonds as in series 3 . This proves that by supporting the formation of the inorganic network, the TM balances the ratio of low- to high-energy siloxane bonds. Therefore, the FTIR results give support to the hypothesis that the increase of the hydrolysis degree catalyses the formation of silicate species with higher degrees of condensations, thus suggesting the formation of more condensed materials. This can primarily be explained by the formation of a higher concentration of reactive silanol groups that subsequently condense into siloxane groups. Nevertheless, from these FTIR results it is impossible to draw definitive conclusions on the effect of the chemistries on the chemical reactions taking place during the sol-gel process or on the resulting morphology of the coatings and their anticorrosion performances. To this end, the sections that follow will investigate and discuss these subjects using additional characterisation techniques.

\section{$3.3{ }^{29}$ Si-NMR analysis}

${ }^{29} \mathrm{Si}-\mathrm{NMR}$ spectra were recorded on 24-h aged sols and are presented in Fig. 4. To quantify the content of the different silicate species for each material series, the signals were integrated and plotted in Fig. 5. One can observe that except for materials I and L, which show a non-negligible quantity of $\mathrm{T}_{0}$ groups ( 2.5 and $15 \%$, respectively), all other materials only exhibit signals in the condensed silicate regions. When comparing the materials in each series, it can be seen that the decrease of the hydrolysis degree tends to increase the $\mathrm{T}_{1}$ species, the highest concentration being observed for materials I and L with a contribution of 32 and $34 \%$ respectively; whereas values of $2.1,2.2,10.8,0.8,1.2$ and $13.2 \%$ were recorded for materials A to $\mathrm{F}$, respectively. It is notable that no $T_{1}$ signals were measured for materials $\mathrm{G}, \mathrm{H}$ and $\mathrm{J}$, whereas sample $\mathrm{K}$ showed a concentration of $17 \%$ in the same chemical shift range. As the hydrolysis degree decreases, the content of $\mathrm{T}_{2}$ species increases within a $5 \%$ range for series $1(48,51$ and $53 \%$ for materials A to C, respectively). However, the content of these groups is dramatically increasing for series 2 and 3 (41 and $53 \%$, respectively). For series 4 , although the $\mathrm{T}_{2}$ content is increased from 75 to $50 \%$ hydrolysis degrees (these groups constituting 32 and $53 \%$ for materials $\mathrm{J}$ and $\mathrm{K}$, respectively), these undergo a decrease for the lowest hydrolysis degree (44\% for material I). A similar behaviour is observed for all series of materials concerning the evolution of $T_{3}$ species. Indeed, as the hydrolysis degree decreases the content of the most condensed moieties regularly decrease, with the most significant variations observed for series 3 and 4, as plotted in Fig. 6. It is, however, noticeable that for these last two series, the decrease of hydrolysis from 75 to $50 \%$ provokes a more pronounced effect on series 4 with a decrease of 55\%, while at the same time series 3 exhibits a similar behaviour to series 1 and 2 with a decrease not exceeding $10 \%$.

The signal of the pure unhydrolysed MAPTMS precursor is found at $-42.8 \mathrm{ppm}$, however, in materials $\mathrm{I}$ and $\mathrm{L}$, we observe more than one $T_{0}$ signal, located at -44 and -45.3 $\mathrm{ppm}$. The presence of these $\mathrm{T}_{0}$ signals indicate that there are unreacted MAPTMS molecules present within other chemical environments. A possible explanation for this is that the MAPTMS has become entrapped within the formed nanoparticles in the sols and remain unhydrolysed. Interestingly, in this spectral region, the three chemical shifts observed in material I, located at $-42.8,-44$ and -45.3 $\mathrm{ppm}$ are found at the exact same position in material $\mathrm{L}$, likely suggesting that material $\mathrm{I}$ and $\mathrm{L}$ are composed of around $70 \%$ of particles with identical morphologies. However, the fact that material $\mathrm{L}$ exhibits an additional signal at a higher chemical shift $(-46.5 \mathrm{ppm})$ indicates that there are nanoparticle populations with a higher density, possibly indicating a slightly greater condensation capability in comparison with material I.

In summary, these results show that within each series of materials, as the hydrolysis degree decreases the formation of the most condensed silicate groups is less favourable. This phenomenon can primarily be explained by the reduction of the quantity of water that leads to a decrease of the formation of reactive silanol groups, which are responsible for the condensation reactions of the siloxane bonds. Knowing that in all cases, the employed hydrolysis degree is under stoichiometry against the reactive alkoxide groups, one can suggest that an in-situ production of water by condensations of silanol groups is taking place to further permit the occurrence of hydrolysis and condensation reactions. Materials I and $\mathrm{L}$ are the only materials that have unreacted $\mathrm{T}_{0}$ groups present in the ${ }^{29} \mathrm{Si}$-NMR spectra, as well as having the highest content of $\mathrm{T}_{1}$ species. This observation shows that the combination of a high TM concentrations and low hydrolysis degrees that we observe a negative impact of the TM on the production of highly condensed silicate species. Two hypotheses can explain this phenomenon: a competition in the hydrolysis reactions and/ or steric hindrance of the zirconium complex. The competition in the hydrolysis reactions of both alkoxides would seem to be more in favour of the ZPO than the organosilane, essentially due to the ZPO's higher hydrophilic character. Indeed, TM alkoxides react spontaneously with silanol groups and water leading to irreversible solids [32]. The introduction of the ZPO within the organosilane matrix, which has been demonstrated by the FTIR results, may take away the silane groups from each other, with a consequence 

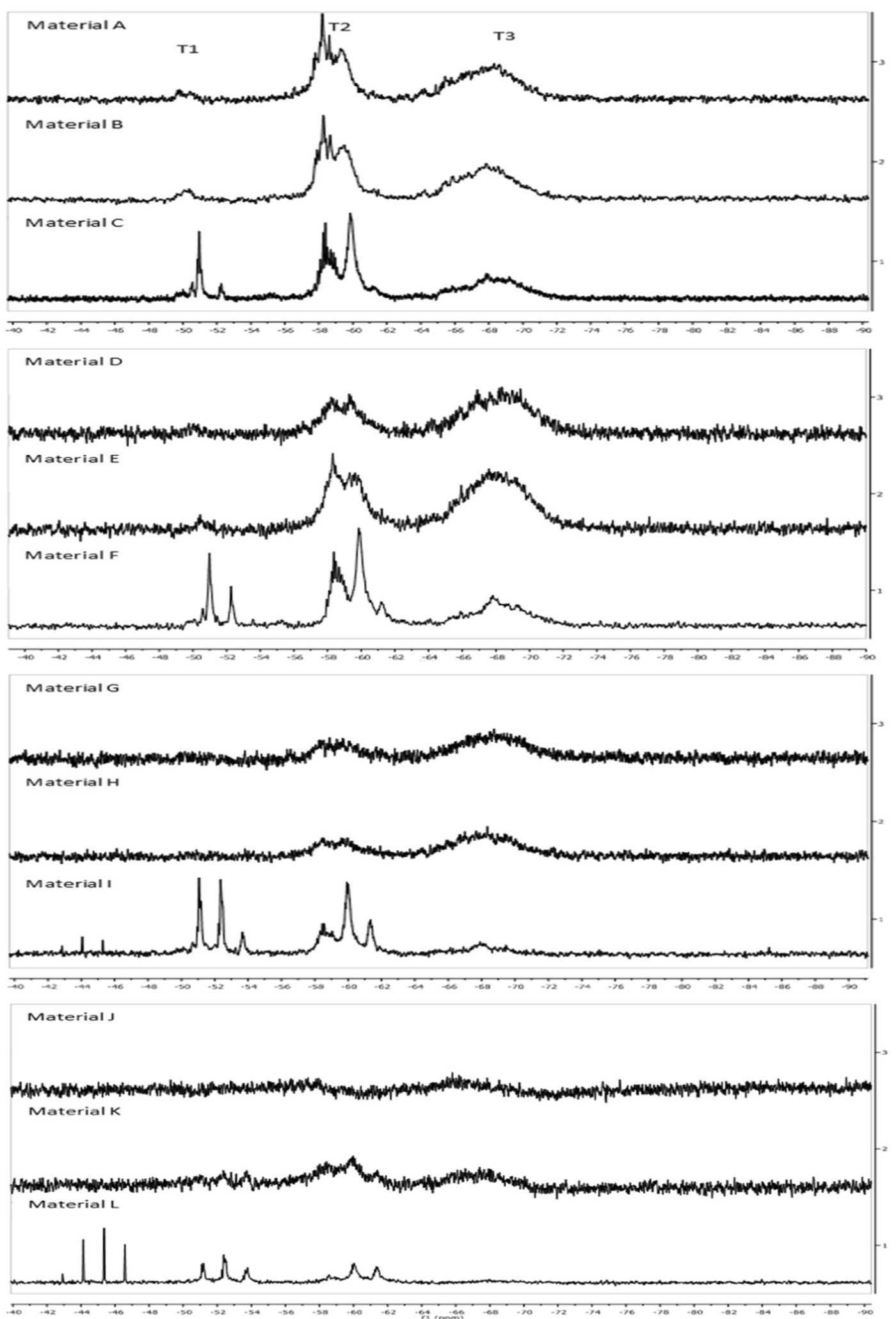

Fig. 4 Liquid state ${ }^{29}$ Si-NMR spectra of 24 -h aged sols A-L

on the direct consumption of the in-situ produced water by the ZPO systems. Based on these explanations, the increase of the $\mathrm{T}_{3}$ groups as the hydrolysis degree increases for series
3 and 4 is explained by the fact that the ZPO groups may fully react at a hydrolysis degree comprised between 50 and $75 \%$, thus leaving the remaining water available for the 


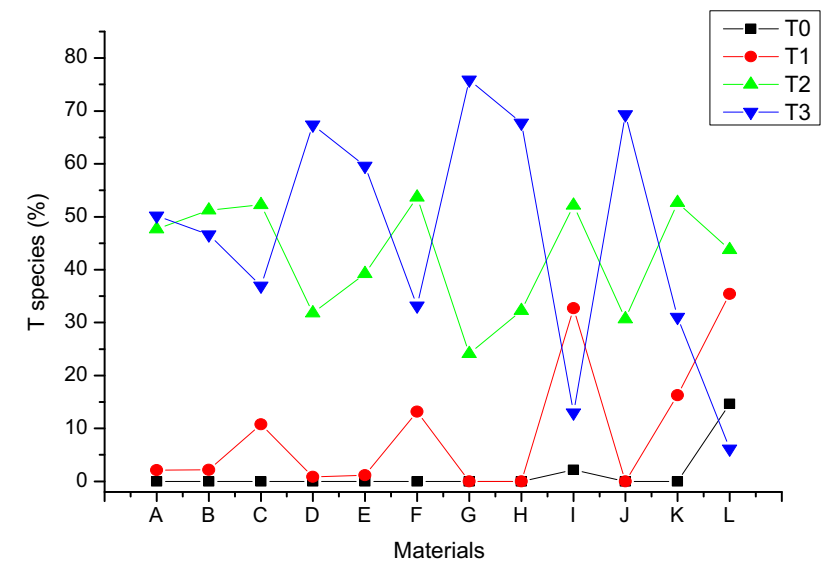

Fig. 5 Evolution of the relative amounts of $T_{0}, T_{1}, T_{2}$ and $T_{3}$ species for 24-h aged sols A-L

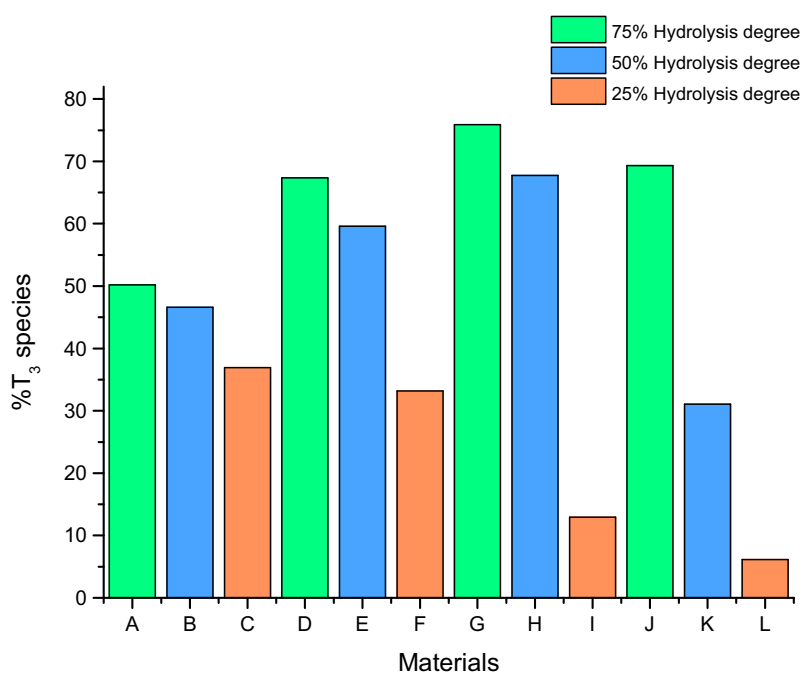

Fig. $6 \% \mathrm{~T}_{3}$ species in 24-h aged sols as calculated from liquid state ${ }^{29} \mathrm{Si}-\mathrm{NMR}$

silane groups to be employed for the further hydrolysis and condensation reactions. In summary, these ${ }^{29} \mathrm{Si}-\mathrm{NMR}$ results show the critical role of the hydrolysis degree in the condensation reactions of the organosilane in the presence of varying concentrations of ZPO. More precisely, at low ZPO concentrations, the decrease of the hydrolysis degree is balanced by the in-situ formation of water that is employed to further pursue the condensation reactions of the organosilane network, thus minimising the decrease of the mostly condensed silicate species. At high ZPO concentrations, the decrease of the hydrolysis degree is negatively impacting the formation of $\mathrm{T}_{3}$ groups for the benefit of $\mathrm{T}_{0}$ and $\mathrm{T}_{1}$ groups because of the competition of hydrolysis reactions that takes place between the two alkoxide precursors. This phenomenon can be balanced by increasing the hydrolysis degree to 50 and $75 \%$ to achieve silicate networks with higher connectivity. The ${ }^{29} \mathrm{Si}$-NMR results show that the degree of connectivity of the silicate species relies strongly on the balance of both the hydrolysis degree and TM content. Therefore, these results support the FTIR conclusions described in section 'FTIR analysis'.

\subsection{DSC analysis}

DSC spectra of the 24-h aged sols between room temperature and $200{ }^{\circ} \mathrm{C}$ are presented in Fig. 7. Three thermal zones can be observed: from room temperature to $100{ }^{\circ} \mathrm{C}$, between 100 and $170{ }^{\circ} \mathrm{C}$ and above $170{ }^{\circ} \mathrm{C}$. These regions are the domain of temperatures where, usually in hybrid solgel materials, the evaporation of the solvents, condensation reactions and glass transition take place, respectively. The endothermic band observed between 20 and $60^{\circ} \mathrm{C}$ represents the evaporation of the alcohols formed during the hydrolysis and condensation reactions (methanol and propanol) and present in the zirconium precursor. It can be seen that the higher the hydrolysis degree the larger the endothermic band, meaning that there is a larger amount of solvent entrapment in these systems. It is worthy to note that as the hydrolysis degree increases a shift towards higher temperatures, with temperature shifts of 10,9 and $4{ }^{\circ} \mathrm{C}$ is observed for series 2, 3 and 4, respectively. This shift can be explained by the formation of a higher content of hydrophilic species such as $\mathrm{Si}-\mathrm{OH}$ and $\mathrm{Zr}-\mathrm{OH}$ groups that contribute to strengthening solvent entrapment by hydrogen bonds with the alcoholic solvents produced from the sol-gel reactions. Apart from series 4, in all other series there is an occurrence of a negative slope between 60 and $120^{\circ} \mathrm{C}$ after the solvent evaporation, suggesting that endothermic phenomena are taking place, probably the thermally catalysed condensation of the residual $\mathrm{Si}-\mathrm{OH}$ and $\mathrm{Zr}-\mathrm{OH}$ groups into $\mathrm{Si}-\mathrm{O}-\mathrm{Zr}$ and $\mathrm{Si}-\mathrm{O}-\mathrm{Si}$ groups and associated release of the water and alcohol formed. In the region $100-170^{\circ} \mathrm{C}$, the systems with a $25 \%$ hydrolysis degree (materials C, F, I and L) display the largest negative slope. This negative slope decreases with an increasing hydrolysis degree in all systems and is almost negligible in the $75 \%$ systems. This signifies that the thermally catalysed condensation reactions observed for the 25 and $50 \%$ hydrolysis degree materials do not take place for the $75 \%$ hydrolysis degree materials as they would have probably occurred during the synthesis in the liquid phase. This result is further confirmation of the role of the hydrolysis degree in the condensation of the solgel network. The exothermic bands located between 175 and $200{ }^{\circ} \mathrm{C}$ represent the glass transition temperature $(\mathrm{Tg})$ of the sols and indicate the full solidification point of the sol-gels. It can be seen overall that as the ZPO increases the $\mathrm{Tg}$ decreases, within a range of $5^{\circ} \mathrm{C}$. Also, for series 1 and 2 the increase of the hydrolysis degree decreases the $\mathrm{Tg}$, whereas the opposite effect is observed for series 3 and 4 . The explanation of these phenomena is very likely to be 
Temperature $\left({ }^{\circ} \mathrm{C}\right)$

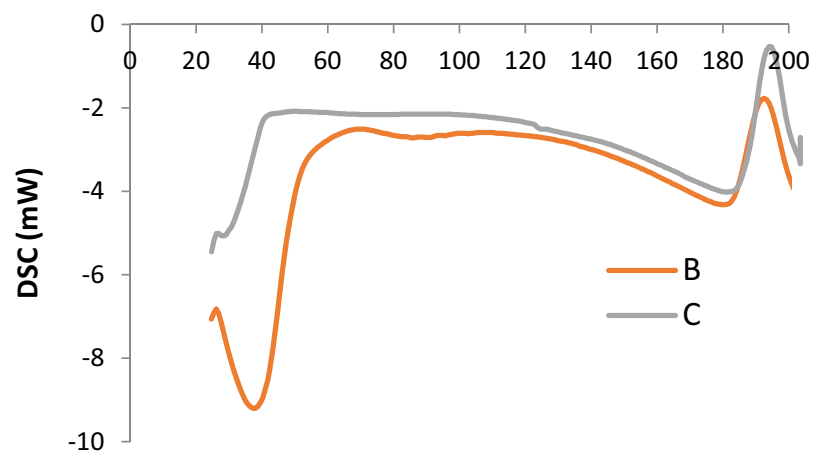

Temperature $\left({ }^{\circ} \mathrm{C}\right)$

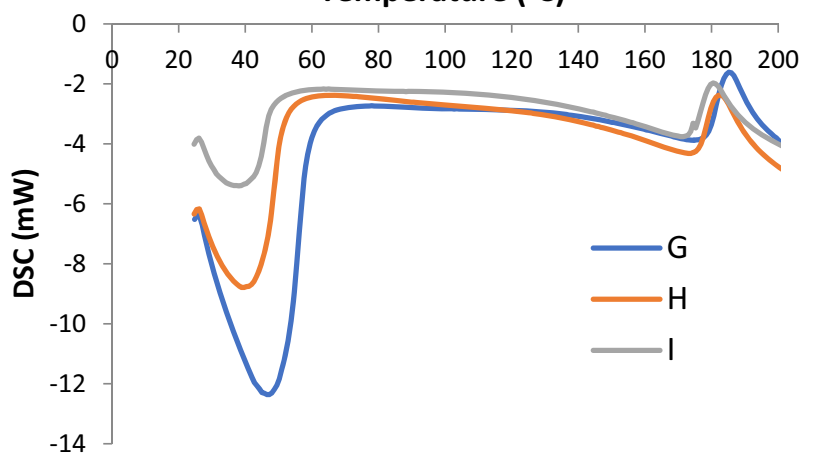

Fig. 7 DSC curves for 24-h aged sols B-L

related to the surface reactivity and process of condensation of the nanoparticle systems initially prepared in the liquid phase. As demonstrated by the FTIR and ${ }^{29} \mathrm{Si}$-NMR characterisations, increasing the hydrolysis degree provokes the formation of more condensed sol-gel systems, the consequence of which would be the minimisation of residual reactive hydroxyl groups at the nanoparticle surfaces. Therefore, the full densification of the most hydrolysed materials would necessitate a higher thermal energy and this would be more pronounced with the more condensed materials as seen here with series 3 and 4 . Based on this hypothesis, series 1 and 2, which show a decrease of $\mathrm{Tg}$ with an increase of the hydrolysis degree may present a higher potential of surface reactivity and thermal condensation due to a higher content of hydroxyl reactive groups permitted by a lower condensation in the liquid phase. In summary, the DSC results confirm the FTIR and ${ }^{29} \mathrm{Si}$-NMR results that it is possible by balancing the hydrolysis degree and the ZPO concentration, the condensation of the materials can be controlled.

\subsection{SEM/EDX analyses}

All coatings were found to be homogenously deposited on the aluminium alloy with a thickness close to $5.5 \mu \mathrm{m}$, as shown in the SEM image of material $\mathrm{K}$ represented in
Temperature $\left({ }^{\circ} \mathrm{C}\right)$
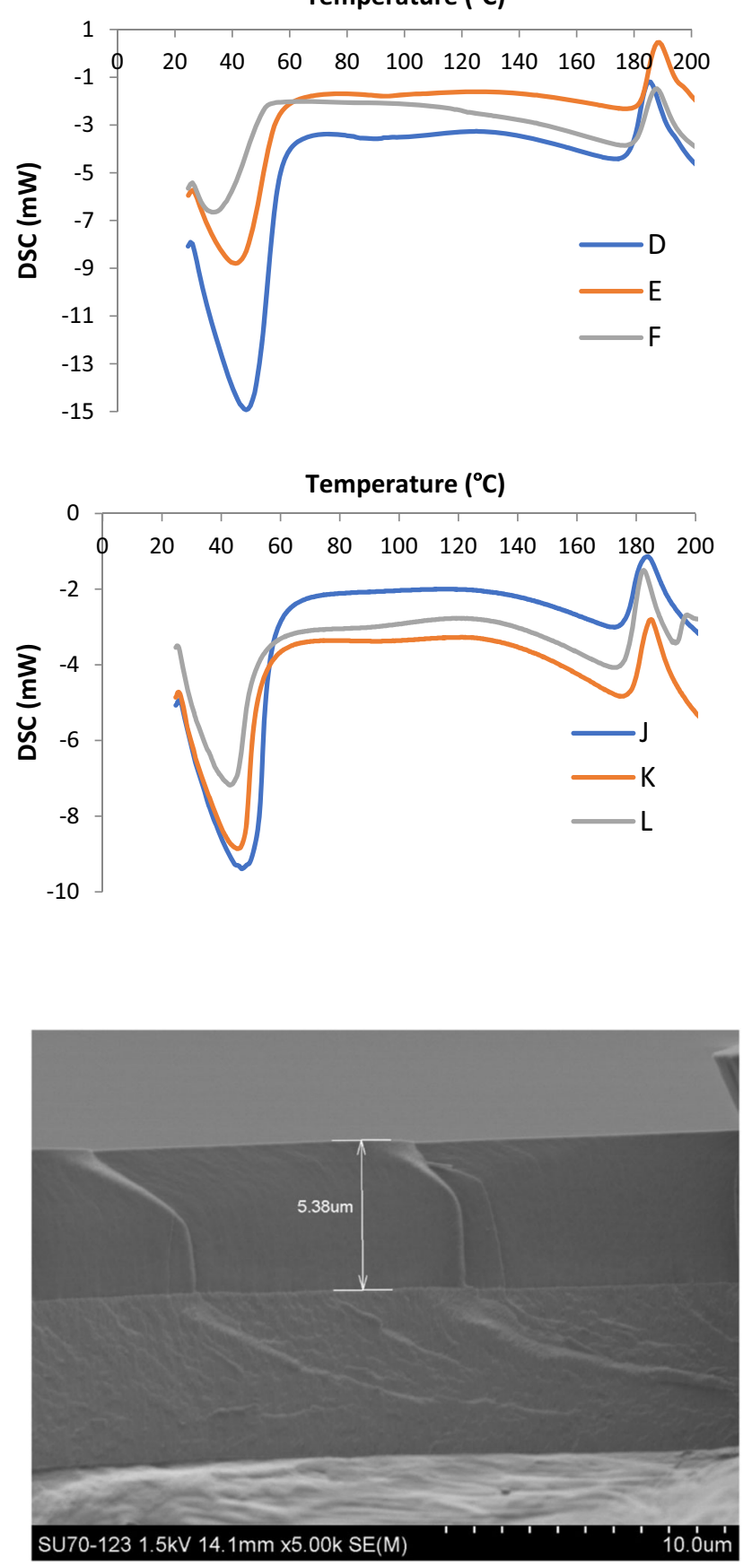

Fig. 8 SEM image of coating $K$

Fig. 8. EDX analysis of the coatings' cross-section (Fig. 9) shows a uniform distribution of the main elements contained in the sol-gel precursors (carbon, silicon and zirconium) and the main elements of the alloy (aluminium, copper and magnesium) seen at the bottom of the image. The uniform distribution of all chemical species within the coating demonstrates the homogeneity of the materials and would further suggest that the silicon and zirconium precursors are chemically linked, as confirmed above by the FTIR results. 


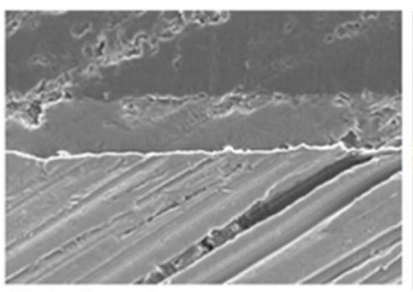

Electron Image 1

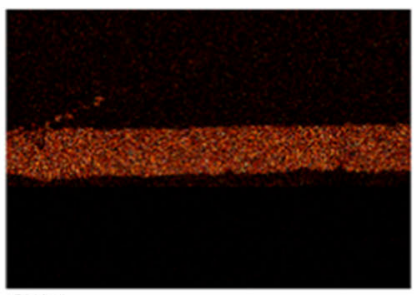

Si Ka1

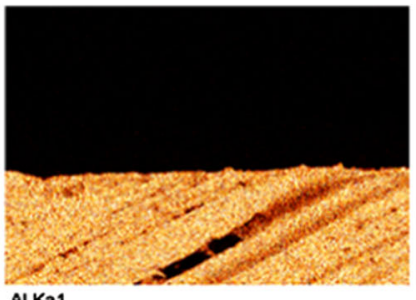

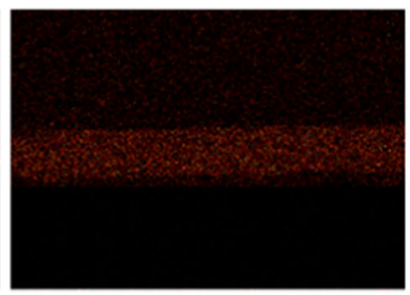

Zr La1

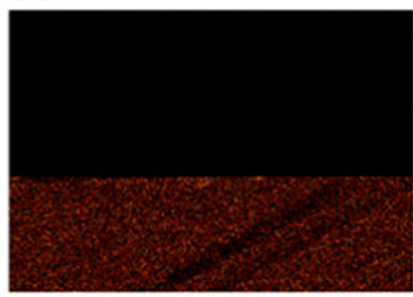

Mg Ka1_2

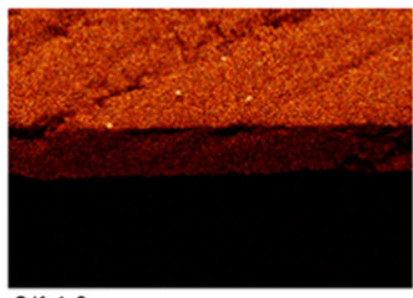

CKa1_2

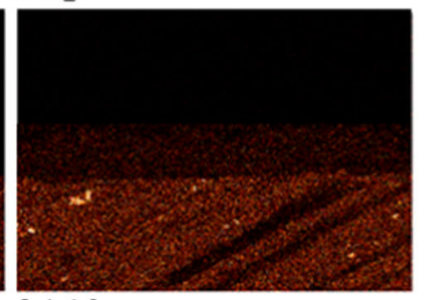

Fig. 9 EDX analysis of coating $\mathrm{K}$

\subsection{AFM analysis}

The surface roughness of the coatings, measured by AFM, are plotted in Fig. 10. It was observed that the materials prepared with a $50 \%$ hydrolysis degree (B, E, H and K) exhibited the lowest surface roughness, ranging from 31 to $55 \mathrm{~nm}$, with material $\mathrm{H}$ showing the lowest roughness. An increase in roughness values is observed for a $25 \%$ hydrolysis degree $(\mathrm{C}, \mathrm{F}, \mathrm{I}$ and $\mathrm{L})$, ranging from 38 to $77 \mathrm{~nm}$, followed by a further increase when the hydrolysis degree reaches $75 \%(D, G$ and $J)$ where surface roughness values from 40 to $105 \mathrm{~nm}$ were observed. Coating roughness of sol-gel materials usually relies on the particle size and homogeneity and on the process of condensation of these particles during the coating deposition and curing. Knowing that the peak intensity for the particle size distribution for material $\mathrm{H}$ is the same for material $\mathrm{B}, \mathrm{E}$ and I, and slightly bigger than materials $\mathrm{C}$ and $\mathrm{F}$, the particle size cannot explain the observed differences. Therefore, the differences can only be due to a more favourable condensation process of the nanoparticle systems taking place in material $\mathrm{H}$.

\subsection{Electrochemical impedance spectroscopy}

The anticorrosion properties of the fabricated coatings on AA2024-T3 alloys are characterised by EIS and the results displayed in a bode plot format in Fig. 11. The bode plots were recorded for all coatings after exposure to a $3.5 \%$ $\mathrm{NaCl}$ electrolyte for 0,72 and $168 \mathrm{~h}$. One can observe that after $0 \mathrm{~h}$ of exposure, one time constant can be distinguished at low frequency for all materials $\left(<10^{1} \mathrm{~Hz}\right)$, except for materials $\mathrm{C}, \mathrm{F}$ and $\mathrm{L}$, which exhibit an additional time constant at higher frequencies $\left(>10^{1.5} \mathrm{~Hz}\right)$. This translates that immediately after the immersion within the electrolyte, coatings $\mathrm{C}, \mathrm{F}$ and $\mathrm{L}$ undergo a formation of an oxide layer at the metal/coating interface, suggesting these materials

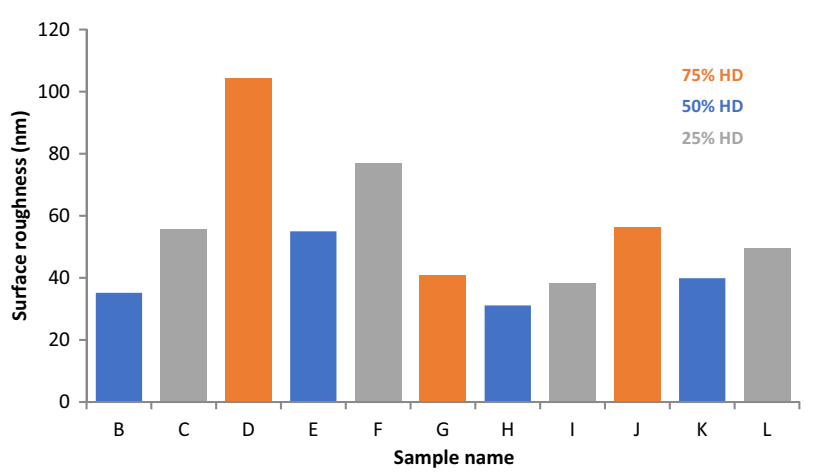

Fig. 10 Roughness values for coatings A-L, as measured from AFM images

exhibit high permeability in comparison with the other materials. In addition, the fact that the second time constant is observed at a slightly higher frequency for coatings $\mathrm{C}$ and $\mathrm{I}$ in comparison with coating $\mathrm{L}$ indicate that coatings $\mathrm{C}$ and I would be more sensitive to corrosive species likely due to higher porosities than coating L. After $0 \mathrm{~h}$ of exposure, all materials exhibit at least one time constant at high frequency $\left(>10^{1} \mathrm{~Hz}\right.$ ), proving that the alteration of the metal/ coating interface has taken place in all materials. After $168 \mathrm{~h}$ of exposure, similar time constants for all samples are observed after $0 \mathrm{~h}$ of exposure, however, there is a shift toward higher frequencies clearly noticeable demonstrating the extension of the corrosion phenomena. Therefore, these results show that coatings $\mathrm{C}, \mathrm{F}$ and $\mathrm{L}$ would be the coatings that are the most vulnerable to early corrosion, whereas the other coatings also corrode but at higher exposure times. However, bode plot analyses are insufficient to discriminate the coatings formulations against their anticorrosion behaviour and would need to be corroborated to impedance results at low frequency, as plotted in Fig. 12. One can see that for all coatings the impedance values decrease as a 


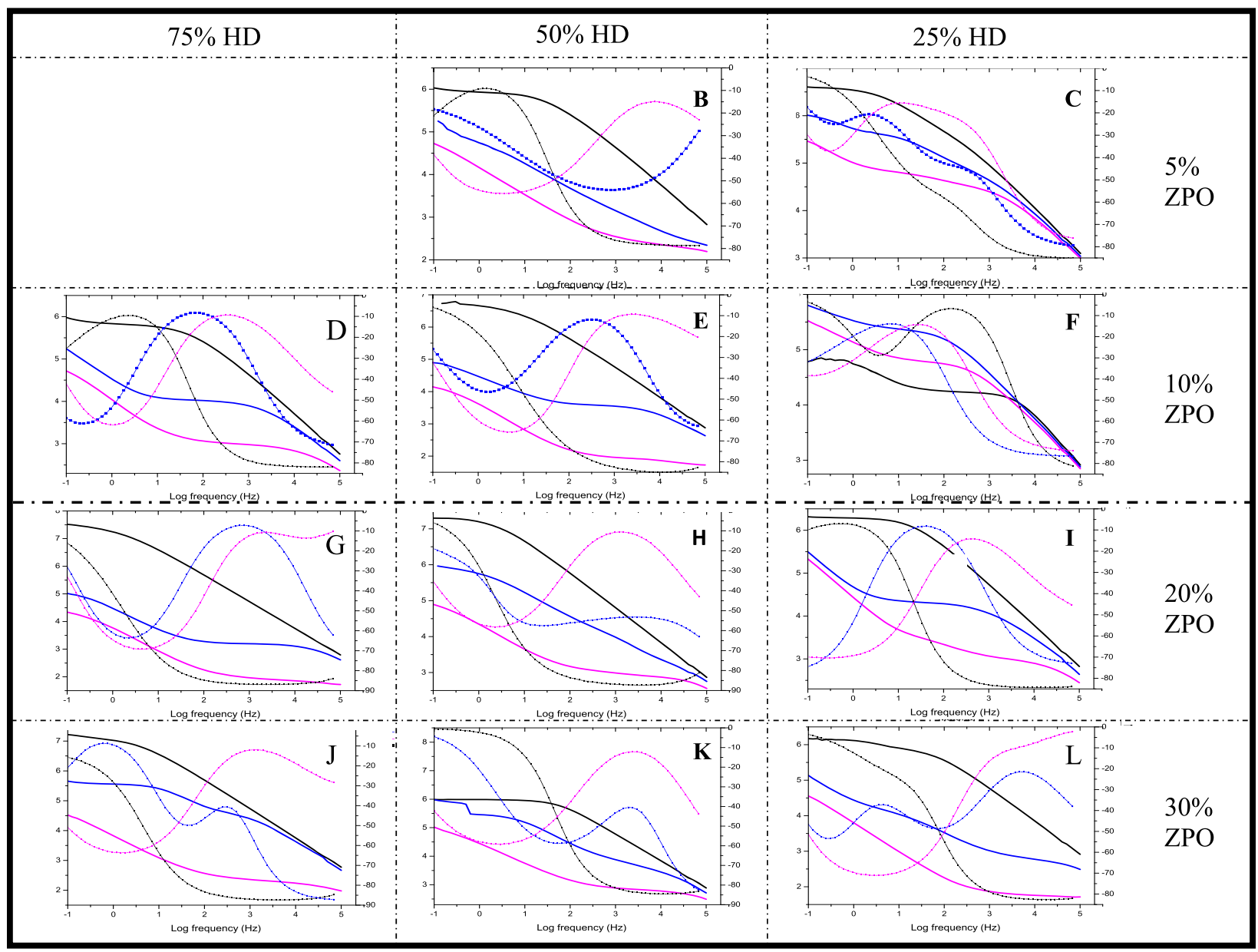

Fig. 11 Bode plots of coatings B to L after $0 \mathrm{~h}$ (black curves), $72 \mathrm{~h}$ (blue curves) and $168 \mathrm{~h}$ (pink curves) of immersion in dilute Harrison's solution (colour figure online)

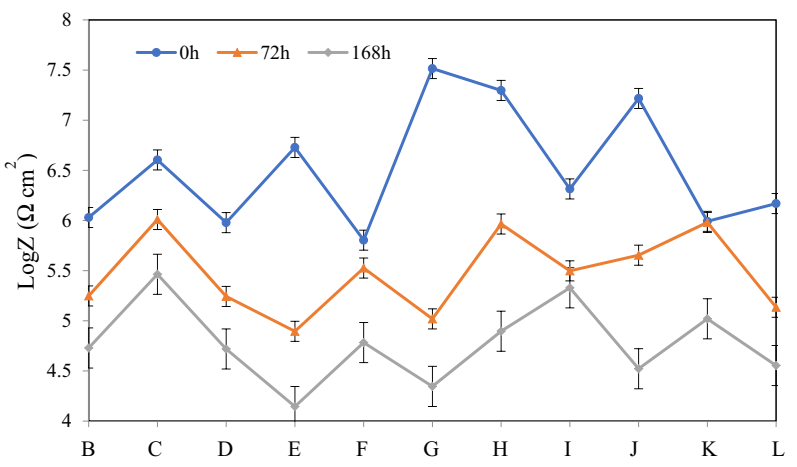

Fig. 12 Representation of the impedance at frequency $10^{-1} \mathrm{~Hz}$ for materials B-L

function of exposure time and impedance values are found to be maximum for samples $\mathrm{I}, \mathrm{H}$ and $\mathrm{J}$, recorded around $10^{7.25} \Omega \mathrm{cm}^{2}$ at exposure time of $0 \mathrm{~h}$, whereas all the other coatings range between $10^{6}$ and $10^{6.5} \Omega \mathrm{cm}^{2}$. Interestingly, sample $\mathrm{K}$ shows no evolution of its impedance value from 0 to 72-h exposure times in comparison with the other samples. After $168 \mathrm{~h}$ of exposure, impedance values for all samples range between $10^{4.5}$ and $10^{5} \Omega \mathrm{cm}^{2}$ except for samples $C$ and I that are found close to $10^{5.5} \Omega \mathrm{cm}^{2}$ while sample $\mathrm{E}$ is at slightly lower impedance values. These results suggest that the duration of exposure tends to level the performances of the coatings in terms of corrosion resistances regardless of the materials formulations, including differences in HD and ZPO concentration. At this stage the hypothesis of difference in the electrolyte kinetics for crossing the coatings to reach the aluminium substrate may be the most obvious explanation to the observed results. This hypothesis would be in relation to the coatings densities and would be particularly valid for the early exposure time. Coatings $\mathrm{G}, \mathrm{H}$ and $\mathbf{J}$ were found to exhibit the highest degree of connectivity (which can be seen as an increase in the content of high-energy siloxane bonds in these materials, as per FITR results) and show the best anticorrosion performances after $0 \mathrm{~h}$ of exposure. However, this hypothesis is not valid for some of the coatings that were found to show a lower degree of connectivity, such as coatings $\mathrm{C}$ and $\mathrm{I}$ that have a greater anticorrosion activity 
after $168 \mathrm{~h}$ of exposure than coatings $\mathrm{G}, \mathrm{H}$ and J. Indicating that the condensation of the coatings is not the only parameter explaining the barrier properties of the coatings and thus another phenomenon is also taking place in parallel. If the connectivity and consequently the density of the coatings is in question for the longer exposure times, it is likely that the origin of these differences is in relation with the functional and/or the mechanical nature of the materials, resulting in different reactivities with the metal surface, thus in differences in the surface areas covered by the materials on the metal. Indeed, the materials with low degrees of connectivity would be composed of more flexible nanoparticles, thus exhibiting a higher deformation capability during the deposition process to enhance surface area coverage on the metal, as sketched in Fig. 13. Furthermore, the lower HD of these materials provides a greater potential of reactivity with the metal surface by the formation of covalent oxo-bridges with the hydroxyl activated aluminium surface as outlined in Eqs 1 and 2 below.

$$
\mathrm{Si}-\mathrm{O}-\mathrm{CH}_{3}+\mathrm{Al}-\mathrm{OH} \rightarrow \mathrm{Si}-\mathrm{O}-\mathrm{Al}+\mathrm{HO}-\mathrm{CH}_{3}
$$

$\mathrm{Zr}-\mathrm{O}-\mathrm{C}_{3} \mathrm{H}_{7}+\mathrm{Al}-\mathrm{OH} \rightarrow \mathrm{Zr}-\mathrm{O}-\mathrm{Al}+\mathrm{HO}-\mathrm{C}_{3} \mathrm{H}_{7}$

In summary, analysis of the electrochemical results has highlighted the occurrence of two physicochemical phenomena over short and longer exposure times of the coatings to the electrolyte solution, which primarily rely on the structure of the materials. The higher condensed coatings would exhibit a greater corrosion resistance at the early start of the testing, due to their higher impermeable character. Over longer exposure times, the lower densified coatings would behave similarly to the more densified coatings, probably due to their better ability to cover higher surface areas of the metal during the coating fabrication process.

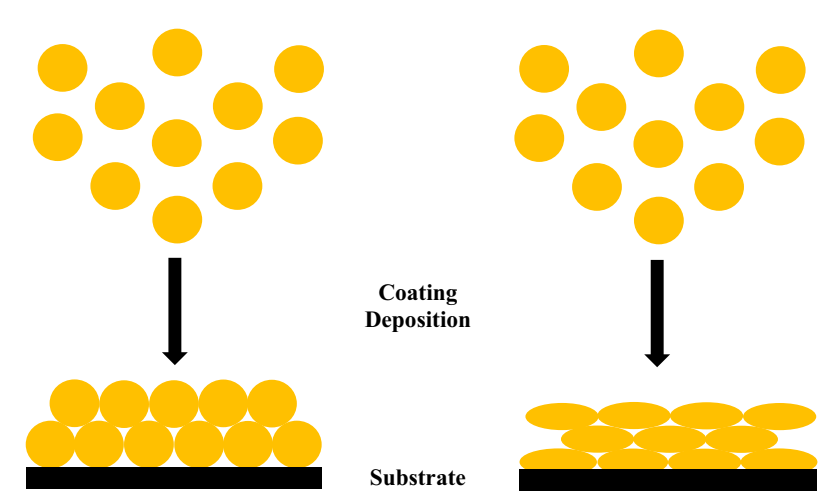

Fig. 13 Representation of how the nanoparticles density can have an effect on the bonding with the substrate, (left are more dense particles and the right are less dense more flexible particles)
NSS testing will be performed to further confirm or disconfirm the electrochemical results.

\subsection{Neutral salt spray}

NSS was operated according to ISO 9227. The samples were checked after 27, 48 and $144 \mathrm{~h}$ of exposure to the salt spray fog, as shown in Fig. 14. To quantify the corrosion resistance of the coatings, the number of pits per $\mathrm{dm}^{2}$ as a function of exposure time for each coating has been represented in Fig. 15.

After $24 \mathrm{~h}$ of exposure, coatings $\mathrm{D}, \mathrm{H}$ and $\mathrm{J}$ show no sign of corrosion, whereas coatings E, F, I, K and L exhibit $<3$ pits per $\mathrm{dm}^{2}$. At the same time, coatings $\mathrm{B}$ and $\mathrm{C}$ show 9 and 22 pit per $\mathrm{dm}^{2}$. Within a specific exposure time, it is observed that samples prepared with $25 \%$ HD (coatings C, $\mathrm{F}, \mathrm{I}$ and $\mathrm{L}$ ) undergo a fast increase in the number of pits per $\mathrm{dm}^{2}$ that exceed 100 after $144 \mathrm{~h}$ of exposure. However, samples prepared with a minimum HD of $50 \%$ remain under 50 pits per $\mathrm{dm}^{2}$ at the same exposure time, with samples $\mathrm{H}$ and $\mathbf{J}$ having $<30$ and more remarkably coating $\mathrm{K}$ exhibiting a number of pits per $\mathrm{dm}^{2}$ close to 10 . Moreover, as this sample was also found to be the most stable at up to $72 \mathrm{~h}$ of exposure in the EIS testing, it is evident that it is the most corrosion-resistant coating of all materials investigated in this study. Therefore, the NSS results highlight that the condensation of the materials has a more prevalent effect on the anticorrosion barrier properties of the coatings than the proposed higher coverage area hypothesis proposed to explain the similar performances of all coatings over a long-term exposure in the above electrochemical study. Finally, by corroborating the electrochemical and NSS results, it is evident that the electrochemical testing would be a more aggressive corrosion accelerated technique than NSS.

\section{Conclusion}

The goal of this study was to identify the impact of the hydrolysis degree on the structure and morphology of a hybrid material composed of an ormosil and a zirconium complex. In parallel, the structures of the materials were also altered by varying the content of the zirconium complex. The cumulative effects that the hydrolysis degree and TM concentration have on the structures of the materials have been thoroughly investigated by FTIR and ${ }^{29} \mathrm{Si}-\mathrm{NMR}$ spectroscopies. These techniques have demonstrated the occurrence of an interesting behaviour, which to our knowledge was not previously demonstrated in the chemistry of sol-gel materials; namely the formation of materials with dramatically different morphologies depending on the conditions of hydrolysis and concentration of the ZPO 


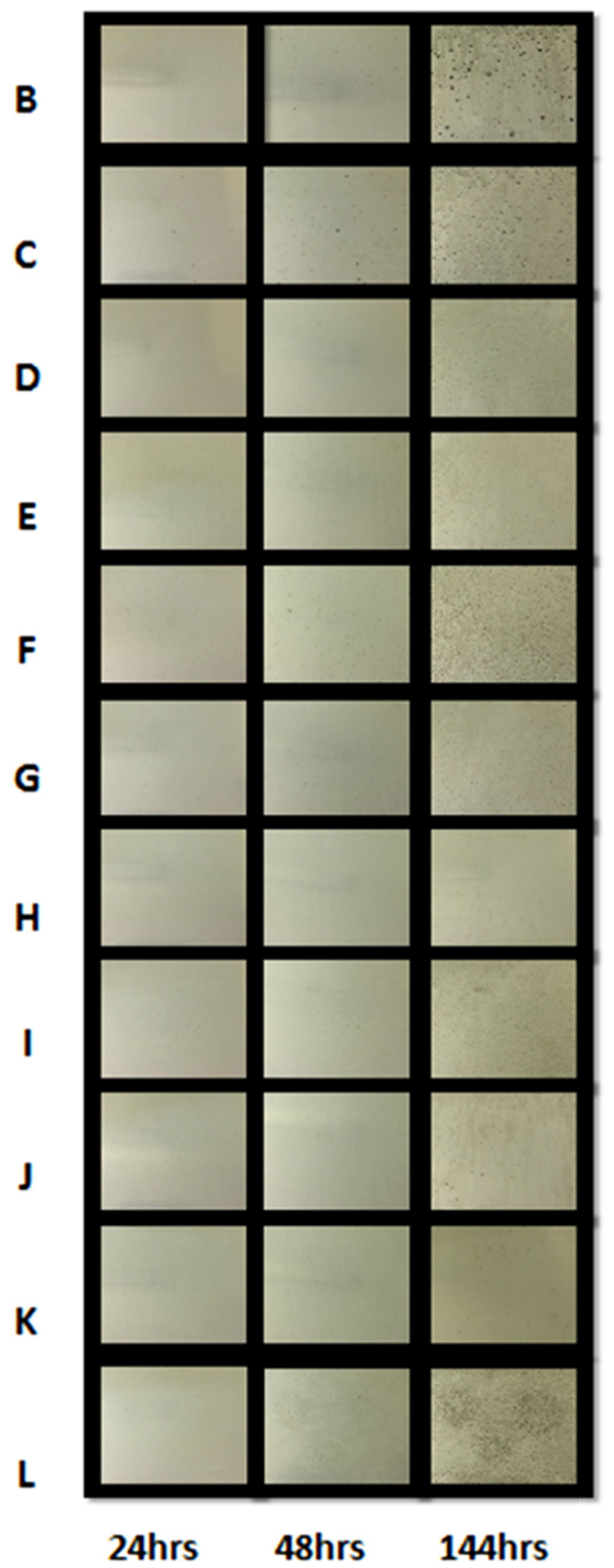

Fig. 14 Images of coatings B-L after 24, 48 and 144-h NSS exposure

within the organosilane matrix. The FTIR results showed that the siloxane bonds region located between 1000 and $1200 \mathrm{~cm}^{-1}$ is composed of four overlapping bands at 1010 , 1030,1055 and $1080 \mathrm{~cm}^{-1}$, which were attributed to the formation of siloxane bonds situated in networks of varying degrees of connectivity. The formation of high-energy

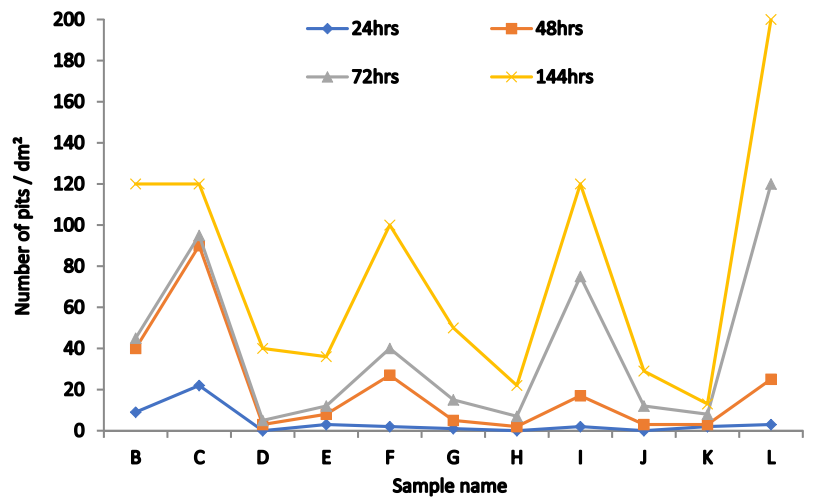

Fig. 15 Number of pits per $\mathrm{dm}^{2}$ for coatings B to L after 24, 48, 72 and 144-h NSS exposure

siloxane bonds and silicon-zirconium oxide groups was found to increase as both the hydrolysis degree and ZPO content was increased, at the expense of lower energy siloxane bonds. The content of high-energy siloxane bonds and silicon-zirconium oxide groups were found to be maximum for the 20 and 30\% ZPO materials, respectively. The anticorrosion analyses have evidenced that the coatings containing $30 \%$ of ZPO and prepared with a HD of $50 \%$ exhibits the best corrosion resistance. This would suggest that this material would exhibit the strongest barrier properties due to a more favourable condensed structure.

However, further studies are required to better correlate the formulations of organosilanes and TM based hybrid solgel materials to their morphologies and corrosion resistances. These will include variation of the $\mathrm{pH}$ of synthesis along with the hydrolysis degree, the effect of the organic functionality in the ormosil, as well as the nature of the TM complex. Also, other characterisation techniques, such as Brunauer-Emmett-Teller (BET), to determine the density of the nanomaterials, and ${ }^{29} \mathrm{Si}-\mathrm{NMR}$ and ${ }^{91} \mathrm{Zr}$-NMR to characterise the structure of the hybrids in the solid state will be needed. XPS and EXAFS characterisation techniques will be essential to identify the surface composition of the coatings to attain more information on the aggregation mechanisms of the particles during the coatings fabrications.

\section{Compliance with ethical standards}

Conflict of Interest The authors declare that they have no conflict of interest.

\section{References}

1. Official Journal of the European Union "Commission Directive 2011/37/EU", OJ L 269

2. EPA Federal Register (1995) National Emission Standards for Hazardous Air Pollutants for Source Categories: Aerospace Manufacturing and Rework Facilities, 60:45947 
3. Pommiers S, Frayret J, Castetbon A, Potin-Gautier M (2014) Corros Sci 84:135-146

4. Hornberger H, Virtanen S, Boccaccini AR (2012) Acta Biomater 8:2442-2455

5. Amini R, Sarabi AA (2011) Appl Surf Sci 257:7134-7139

6. Figueira RB, Fontinha IR, Silva CJR, Pereira EV (2016) Coatings 6(1):12

7. Amiri S, Rahimi A (2016) Iran Polym J 25:559-577

8. Marques ME, Mansur AAP, Mansur HS (2013) Appl Surf Sci 275:347-360

9. Su H-Y, Chen P-L, Lina C-S (2016) Corros Sci 102:63-71

10. Chichkov BN, Farsari M (2009) Nat Photonics 3:450-452

11. Oubaha M, Gorin A, McDonagh C, Duffy B, Copperwhite R (2015) Sens Actuators B 221:96-103

12. Fedel M, Callone E, Fabbian M, Deflorian F, Dirè S (2017) Appl Surf Sci 414:82-91

13. Moutarlier V, Neveu B, Gigandet MP (2008) Surf Coat Technol 202:2052

14. Upadhyay V, Bergseth Z, Kelly B, Battocchi D (2017) Coatings 7:86

15. J Colreavy, B Duffy, PCR Varma, H Hayden, M Oubaha Patent "Sol-gel coating compositions and their process of preparation" EP 2220176 A2

16. Lebeau B, Innocenzi P (2011) Chem Soc Rev 40:886-906

17. Ferreira RAS, André PS, Carlos LD (2010) Opt Mater 32:1397-1409

18. Elmaghrum S, Gorin A, Kribich RK, Corcoran B, Copperwhite R, McDonagh C, Oubaha M (2013) Sens Actuators B 177:357-363

19. Oubaha M, Kavanagh A, Gorin A, Bickauskaite G, Byrne R, Farsari M, Winfield R, Diamond Dermot, McDonagh Colette, Copperwhite Robert (2012) J Mater Chem 22:10552
20. Delattre L, Dupuy C, Babonneau F (1994) Characterization of the hydrolysis and polymerization processes of methacryloxypropyltrimethoxysilane - code: BP18. J Sol-Gel Sci Technol 2 (1-3): $185-188$

21. Gualandris V, Babonneau F, Janicke MT, Chmelka BF (1998) NMR studies on hydrolysis and condensation reactions of alkoxysilanes containing $\mathrm{Si}-\mathrm{H}$ bonds. J Sol-Gel Sci Technol 13:75-80

22. Babonneau F, Maquet J (2000) Nuclear magnetic resonance techniques for the structural characterization of siloxane-oxide hybrid materials. Polyhedron 19(3):315-322

23. Cullen M, Morshed M, O'Sullivan M, MacHugh E, Duffy B, Oubaha M (2017) J Sol-Gel Sci Technol 82(3):801

24. Copperwhite R, O'Sullivan M, Boothman C, Gorin A, McDonagh C, Oubaha M (2011) Microfluid Nanofluid 11:283-296

25. Morrow BA, McFarlan AJ (1992) J Phys Chem 96:1395-1400

26. Elvira MR, Alejandra Mazo M, Tamayo A, Rubio F, Rubio J, Oteo JL (2013) J Chem Eng 7:120-131

27. Pickup DM, Mountjoy G, Wallidge GW, Newport RJ, Smith ME (1999) Phys Chem Chem Phys 1:2527

28. Hanuhov T, Asulin E, Gvishi R (2017) J Non-Cryst Solids 471:301

29. Lerot L, Low PF (1976) Clays Clay Miner 24:191-199

30. Handke M, Kwaśny M (2014) Vib Spectrosc 74:127-131

31. Handke M, Kwas̈ny M (2014) Infrared spectroscopic study of octahydridooctasilsesquioxane hydrolytic polycondensation. Vib Spectrosc 74:127-131

32. Delattre L, Babonneau F (1997) Chem Mater 9:2385-2394 